\title{
Mechanical and Physical Properties of Regenerated Biomass Composite Films from Lignocellulosic Materials in Ionic Liquid
}

\author{
Kehong Zhang, ${ }^{\text {a,b,* }}$ Hui Xiao, ${ }^{\text {a }}$ Yuhang Su, ${ }^{\mathrm{b}}$ Yanrong Wu, ${ }^{\mathrm{a}}$ Ying Cui, ${ }^{\mathrm{a}}$ and Ming Li ${ }^{\mathrm{a}}$
}

\begin{abstract}
As an important sustainable source of biomass, lignocellulosic materials are highly recalcitrant to biotransformation, which limits their use and prevents economically viable conversion into value-added products. Ionic liquids (ILs) have emerged as attractive solvents for lignocellulosic biomass pretreatment in the production of biochemical feedstocks. In this work, a mixture of wood powder and waste paper was dissolved in the ionic liquid 1-allyl-3-methylimidazolium chloride ([AMIM]CI). Composite films were made from the regenerated lignocellulosic materials in $[\mathrm{AMIM}] \mathrm{Cl}$ by adjusting the ratio of the raw materials. The physical and mechanical properties of biomass composite films were determined by optical microscopy (OM), Fourier transform infrared (FTIR) spectra, X-ray diffraction (XRD), and tensile strength tests. The results indicated that lignocellulosic materials were dissolved in [AMIM]Cl by destroying interand intramolecular hydrogen bonds between lignocelluloses. With increasing waste paper cellulose content, the dissolution of the fir powder in [AMIM]Cl was accelerated, and the tensile strength and elongation at break of the composite films increased. The rate of dissolution initially rose rapidly with increasing content of waste paper cellulose content, but the rate leveled off when the content was above $40 \%$. This research highlights new opportunities for biodegradable composite films made from waste biomass.
\end{abstract}

Keywords: Lignocellulosic materials; Ionic liquid; Composite films; Mechanical and physical properties

Contact information: a: School of Light Textile Engineering and Art, Anhui Agricultural University,

230036, China; b: Fujian Universities and Colleges Engineering Research Center of Soft Plastic

Packaging Technology for Food, 350300, China; *Corresponding author: zkh@ahau.edu.cn

\section{INTRODUCTION}

Due to the growing global awareness of the environment and the idea of sustainability, the efficient utilization of biomass has received an increase in attention. Lignocellulosic biomass, such as agricultural wastes, wood residues, and energy crops, is considered to be the most available and renewable resource for the production of biofuels and value-added bio-based products (Himmel et al. 2007; Behera et al. 2014). Wood is a renewable source made of $35 \%$ to $50 \%$ cellulose, $5 \%$ to $30 \%$ lignin, up to $35 \%$ hemicelluloses, and a small percentage of extractives. These components are assembled in a complex three-dimensional structure that is resistant against chemicals and microbial attack, making it difficult to hydrolyze. The insolubility of wood in common solvents has hampered its utilization and prevents an economically feasible conversion into valueadded products.

Dissociation and separation of the main components of wood is needed to produce high value products from lignocellulosic biomass (Abdulkhani et al. 2013). Traditionally, 
a strong base or mineral acids have been used to exploit the lignocellulosic materials. The severity, irreversibility, and environmental pollution of conventional processes lead to inadequate utilization of non-cellulose biopolymers, i.e., lignin and hemicelluloses. To overcome these obstacles, several pretreatment strategies have been advanced in recent years, e.g., physical, chemical, physicochemical, hot water, and biological (Liu and Wyman 2005; Sousa et al. 2009; Binder and Raines 2010; da Silva et al. 2010; Brodeur et al. 2011; Mora-Pale et al. 2011; Imman et al. 2013; Mood et al. 2013; Jönsson and Martín 2016; Bhutto et al. 2017; Kumar et al. 2017). In all cases, the degradation of lignin is unfortunate, resulting in a loss of a functional natural product that comprises $20 \%$ to $35 \%$ of the mass of lignocellulose.

Recently, attention has been drawn toward the application of ionic liquids (ILs) with a strong hydrogen bond destroying ability in the processing of biopolymers (Xie et al. 2007; Mahmood et al. 2017). In contrast with traditional organic solvents, ILs have been applied in the dissolution and regeneration of lignin and lignocellulose, the applications of developing biodegradable composites and advanced materials with lignocellulosic biomass. Swatloski et al. (2002) first demonstrated that ILs can dissolve cellulose. Later studies indicated that many factors, such as species of biomass, particle size, and water content, influence the dissolution of lignocellulosic materials in ILs (Li et al. 2010; Qin et al. 2010; Abdulkhani et al. 2013). The efficiency of dissolution of lignocellulosic biomass in ILs increases with the increase of the dissolving temperature. Cellulose can be dissolved in hydrophilic ILs such as 1-allyl-3-methylimidazolium chloride ([AMIM]Cl) and 1-butyl-3-methylimi-dazolium chloride ([BMIM]Cl) (Wang et al. 2011; Nemestóthy et al. 2017; Rajeev et al. 2018). With the addition of the antisolvent, such as water, acetone, or ethanol, the dissolved cellulose can be regenerated from ILs, and the regenerated cellulose has a lower degree of crystallinity. Compared with native cellulose, the porosity of the regenerated cellulose increases significantly, which results in a greater accessibility to the cellulases by the polysaccharide chains, an increase in digestibility of the material, and a higher yield in the overall conversion process. More recently, Li et al. (2008) has presented meaningful results about the dissolution of full lignocellulosic materials such as wood, corn stalks, bagasse, and rice straw in ILs, followed by cellulose hydrolysis with acid or enzymes. The ability of ILs to dissolve polar and non-polar materials provides integrated bio-processing routes to improve the utilization efficiency of lignocellulosic biomass.

The current work explores the influence of IL treatments and waste paper on the dissolvability of wood powder under mild conditions. The IL [AMIM]Cl, which is a good solvent for lignocellulosic materials, was used to directly dissolve the ball milling fibrous materials (Yoo et al. 2017). The waste paper cellulose was used as adjusting agent to adjust the dissolution rate of wood powder in ILs. With the participation of the waste paper, the dissolved ball milling wood powder in IL was used to make composite films, which were characterized in terms of their physical and mechanical properties.

\section{EXPERIMENTAL}

\section{Materials}

Chinese fir, 5 years in age, was obtained from Huangshan in Anhui Province, China. The pole was cut into small pieces by a saw machine. After being air dried, the wood pieces were processed in a rotary ball mill. The wood powder that can pass through 
the 100 mesh sieve was collected and oven-dried to a constant weight. The waste paper (WP, 98\% $\alpha$-cellulose) was collected from used filter paper in the laboratory with the density of $80 \mathrm{~g} / \mathrm{m}^{2}$ and thickness of $150 \mu \mathrm{m}$. The ionic liquid 1-allyl-3-methylimidazolium chloride ([AMIM]Cl), with the purity of $99.0 \%$, was purchased from the Lanzhou Institute of Chemical Physics (LICP) of the Chinese Academy of Sciences (CAS) (Beijing, China). All other reagents and chemicals were from commercial sources and used as received.

\section{Pretreatment and Dissolution of Waste Paper}

With a suitable ratio, waste paper and $30 \mathrm{wt} \% \mathrm{NaOH}$ solution were poured into Teflon-sealed autoclave and heated at $140{ }^{\circ} \mathrm{C}$ for $2 \mathrm{~h}$. The waste paper cellulose was obtained after removing any dirt on the surface of waste paper and the hemicelluloses. Following the chemical treatments, the waste paper cellulose was filtered and rinsed with distilled water until the solution was neutral, then washed with ethanol and dried in vacuum at $105{ }^{\circ} \mathrm{C}$ and $0.04 \mathrm{MPa}$ for $12 \mathrm{~h}$ before use. The mixture of waste paper cellulose and ILs (mass ratio of 1:9, respectively) was added into a $250 \mathrm{~mL}$ round bottom flask, which was immersed in an oil bath and initially stirred at $80{ }^{\circ} \mathrm{C}$ for $1 \mathrm{~h}$ and then kept at $100{ }^{\circ} \mathrm{C}$ for $40 \mathrm{~min}$ in a nitrogen atmosphere. The transparent dissolved substance was obtained.

\section{Pretreatment and Dissolution of Fir Powder}

The fir powder with a particle size of 100 mesh was extracted by the mixture of ethanol and benzene (1:1, volume ratio) in Soxhlet extractor for $10 \mathrm{~h}$. The extracted fir powder was dried in a vacuum oven at $70{ }^{\circ} \mathrm{C}$ and $0.04 \mathrm{MPa}$ for $12 \mathrm{~h}$. The dried fir powder was added into $25 \mathrm{wt} \% \mathrm{NaOH}$ solution in the sealed PTFE autoclave and treated at $140{ }^{\circ} \mathrm{C}$ for $2 \mathrm{~h}$. Next, the fir powder was filtered and rinsed with distilled water until the solution was neutral, then washed with ethanol and dried in vacuum at $70{ }^{\circ} \mathrm{C}$ and 0.04 $\mathrm{MPa}$ for $12 \mathrm{~h}$. The treated fir powder and ILs were mixed at the mass ratio of 1:19, respectively, and then poured into a $250 \mathrm{~mL}$ round bottom flask with the dissolved waste paper cellulose by the mass ratio as shown in Table 1 . The mixture was stirred at $80{ }^{\circ} \mathrm{C}$ for $4 \mathrm{~h}$ and then kept at $100{ }^{\circ} \mathrm{C}$ for $40 \mathrm{~min}$ in a nitrogen atmosphere. The dissolution system was centrifuged with the speed of $2500 \mathrm{r} / \mathrm{s}$ for $3 \mathrm{~min}$.

Table 1. Sources and Dissolution Conditions of Biomass and Composition of the Composite Films

\begin{tabular}{|c|c|c|c|c|}
\hline Trial & Waste Paper (\%) & Fir Powder $(\%)$ & {$[\mathrm{AMIM}] \mathrm{Cl}^{*}(\%)$} & Dissolution Conditions $\left({ }^{\circ} \mathrm{C}\right)$ \\
\hline 1 & 10.00 & 0.00 & 90.00 & 80 to 100 \\
\hline 2 & 6.67 & 1.67 & 91.66 & 80 to 100 \\
\hline 3 & 4.28 & 2.86 & 92.86 & 80 to 100 \\
\hline 4 & 2.50 & 3.75 & 93.75 & 80 to 100 \\
\hline 5 & 1.11 & 4.44 & 94.45 & 80 to 100 \\
\hline 6 & 0.00 & 5.00 & 95.00 & 80 to 100 \\
\hline * 1-allyl-3-methyl-imidazolium chloride [AMIM]Cl \\
\hline
\end{tabular}

\section{Preparation of Composite Film Made of Fir Powder and Waste Paper}

The dissolved mixture of fir powder and waste paper cellulose was coated with polytetrafluoroethylene (PTFE) film, placed in a mold, and hot pressed for 15 min at 150 
${ }^{\circ} \mathrm{C}$ and $20 \mathrm{MP}$. The composite film of wood powder and waste paper cellulose was placed in distilled water to cool for $1 \mathrm{~h}$. After taking off the PTFE film, the composite film was immersed in distilled water to remove ILs for $24 \mathrm{~h}$ at room temperature. The distilled water was changed every $4 \mathrm{~h}$. The film was placed between two glass panels and vacuum-dried at $40{ }^{\circ} \mathrm{C}(-0.1 \mathrm{MPa})$ for $24 \mathrm{~h}$ until it reached a constant weight. A series of biomass composite films in different mass ratios of fir powder and waste paper cellulose were obtained by this method, as shown in Table 1.

\section{Dissolution Rate of Fir Powder in IL Assisted by Dissolved Waste Paper Cellulose}

The initial mass of fir powder in IL was recorded as $m_{0}$. Assisted by the dissolved waste paper cellulose, the fir powder was partly dissolved in ILs. The residue in the bottom of centrifugal tube was rinsed and filtered with methyl alcohol, then dried in vacuum at $50{ }^{\circ} \mathrm{C}$ and $0.04 \mathrm{MPa}$ for $4 \mathrm{~h}$. The resulting mass of fir powder residue was recorded as $m_{l}$. The dissolution rate $(D)$ of fir powder in ILs was calculated with Eq. 1.

$$
D(\%)=\left(m_{0}-m_{1}\right) / m_{0} \times 100 \%
$$

\section{Mechanical Properties}

All specimens were dried for an additional $24 \mathrm{~h}$ under a vacuum at room temperature to remove residual water. The test specimens for tensile strength were cut from larger samples of synthetic composite film using a scalpel, and the rectangular test samples (30 mm long, $5 \mathrm{~mm}$ wide and $0.1 \mathrm{~mm}$ thick) were obtained. The tensile strength $(\sigma)$ and the elongation at break $(\varepsilon)$ of the films were measured on a universal materialtesting machine equipped with a $100 \mathrm{~N}$ load cell (SANS, Shenzhen, China) at room temperature with test speed of $10 \mathrm{~mm} / \mathrm{min}$. The distance between the jaws was set at 10 $\mathrm{mm}$. The reported $\sigma$ and $\varepsilon$ values were the averages of five measurements.

\section{Fourier Transform Infrared (FT-IR) Spectroscopy}

Fourier transform infrared spectra (transmission) of the biomass composite films were collected on a Bruker Tensor II FTIR spectrometer (Karlsruhe, Germany). All samples were tested in the range of 4000 to $500 \mathrm{~cm}^{-1}$ by the transmission method. After being mixed with potassium bromide $(\mathrm{KBr})$, the samples were ground to a fine powder using a mortar and pestle, then pressed into pellets. The spectra were obtained using an average 32 scans with a spectral resolution of $4 \mathrm{~cm}^{-1}$.

\section{Morphological Study}

The changes in the morphology of the biomass composite films before and after treatment with [AMIM]Cl were observed using MicAO 3DSR digital microscope (Shenzhen, China). The dissolution behavior of cellulose in [AMIM]Cl and the character of the wood powder edge were obtained at 500× magnification.

\section{Crystallinity Measurements}

All treated and untreated biomass composite films were analyzed by X-ray diffraction. The samples were scanned on a XD-3 Discovery diffractometer (PERSEE, Beijing, China) from $2 \theta=5$ to $40^{\circ}$ at a scan speed of $1 \%$ min and a step size of $1^{\circ}$. The cellulose crystallinity index $(\mathrm{CrI})$ was determined via Eq. 2, 


$$
\mathrm{CrI}=\frac{I_{\text {tot }}-I_{a m}}{I_{t o t}} \times 100
$$

where $I_{t o t}$ is the integrated intensity of the entire sample and $I_{a m}$ is the summation of the integrated intensity of the amorphous peak.

\section{RESULTS AND DISCUSSION}

\section{Analysis of Dissolution of Lignocellulosic Materials in [AMIM]CI}

The dissolution of a lignocellulosic biomass mixture made of wood powder and waste paper cellulose in [AMIM]Cl was studied by using the optical microscope, as shown in Fig. 1. In previous studies, wood chips did not dissolve completely, leading to a partial fraction of the sample; the dissolution rate of wood is highly dependent on its particle size (Fort et al. 2007). There is a complex and compact structure that is the wood's cell wall and between the cellulose; hemicelluloses and lignin inhibit the diffusion of ILs into its interior, resulting in only a partial dissolution of wood.

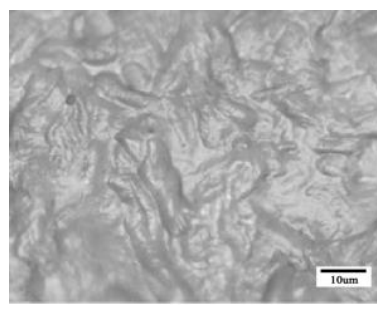

(a) Sample 1

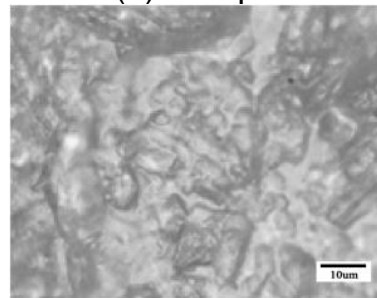

(d) Sample 4

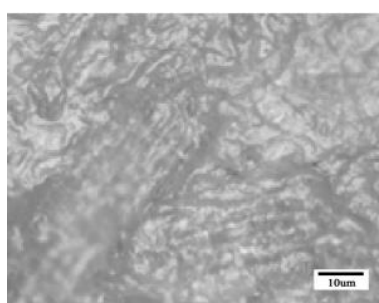

(b) Sample 2

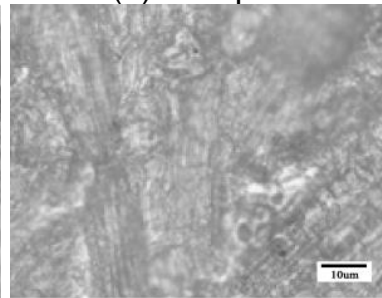

(e) Sample 5

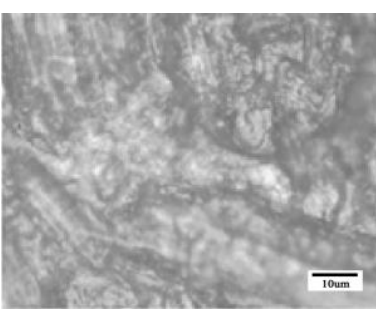

(c) Sample 3

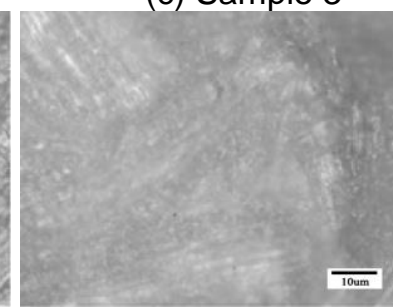

(f) Sample 6

Fig. 1. Optical micrographs of the dissolution of lignocellulosic materials in $[\mathrm{AMIM}] \mathrm{Cl}(\times 500)$

Optical microscopy showed that the solubilization efficiency of lignocellulosic materials in ILs decreased with the increase of wood powder content. When the wood powder content was low, the cellulose chain in the waste paper was easily dissolved in ILs by breaking the extensive hydrogen bonding network of polysaccharides and promoting their dissolution (Remsing et al. 2006). Then, with the increase of wood powder content in mixture, the residual hemicellulose and lignin in wood powder delayed the penetration of ILs, leading to the lignocellulosic materials dissolving more slowly. When the wood powder content was larger than or equal to $80 \%$, the IL, [AMIM]Cl, was not able to effectively interact and dissolve the aromatic character of lignin, thus giving rise to murky solutions.

The effect of waste paper cellulose on accelerating the dissolution of fir powder in ILs is shown in Fig. 2. With the increase of the dissolved waste paper cellulose in the lignocellulosic materials, the content of cellulose will increase, leading to an acceleration of the dissolution of fir powder. The reason is that ILs can break the extensive hydrogen 
bonding network of cellulose and promote the dissolution of cellulose. Following treatment with alkali, some hemicelluloses and lignin in fir powder were removed and the permeability of ILs into the fir powder was increased. Particularly, with the increase of the waste paper cellulose content in the range of $0 \%$ to $40 \%$, the dissolution rate of fir powder significantly increased. When the mass fraction of waste paper cellulose exceeded $60 \%$, the dissolution rate of fir powder increased slowly with the increase of the waste paper cellulose content. As a small amount of dissolved waste paper cellulose were introduced into the mixture of fir powder and $[\mathrm{AMIM}] \mathrm{Cl}$, the freely moving cellulose chain in $[\mathrm{AMIM}] \mathrm{Cl}$ accelerated the breakage of the hydrogen bonding network of polysaccharides in the surface of the fir powder due to the low viscosity of the mixed system. With the increased involvement of waste paper cellulose into the mixture of fir powder and $[\mathrm{AMIM}] \mathrm{Cl}$, the growing viscosity constrained the movement of the cellulose chains and decreased the promotional role of the cellulose chains on the dissolution of fir powder. The growth of the dissolution rate of fir powder in [AMIM]Cl slowed.

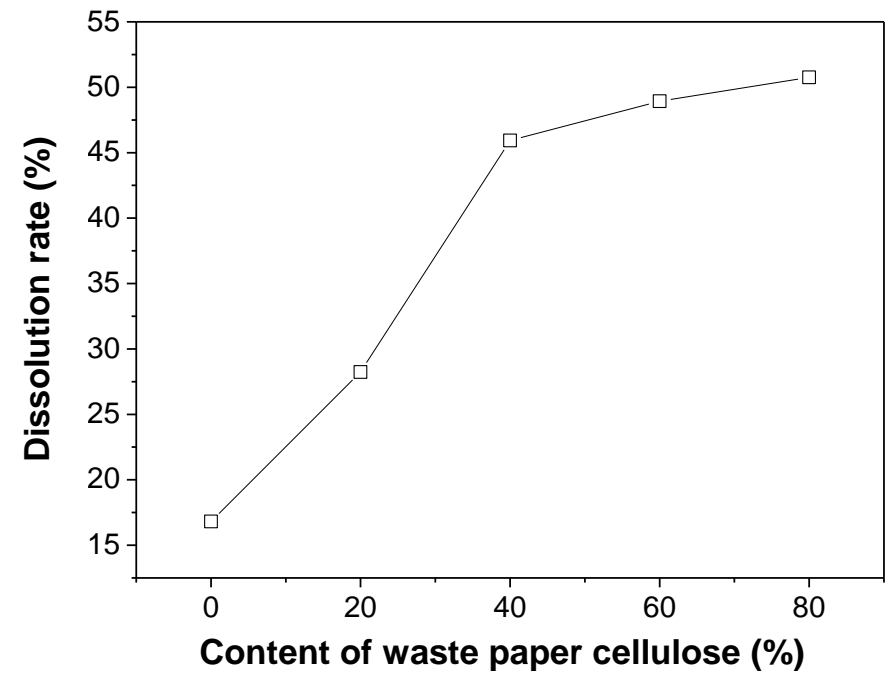

Fig. 2. The effect of content of waste paper cellulose on dissolution of fir powder in [AMIM]CI

\section{FT-IR Characterization}

The FT-IR spectra of composite films regenerated from the dissolved lignocellulosic biomass mixture in $[\mathrm{AMIM}] \mathrm{Cl}$, original waste paper cellulose, and original fir powder are presented in Fig. 3. From Fig. 3(a), it is clear that the peak at 1373 $\mathrm{cm}^{-1}$ was associated with the C-H bending, and the absorption at $2902 \mathrm{~cm}^{-1}$ was due to the C-H stretching (Al Mualla et al. 2016). The band strength ratio of regenerated waste paper cellulose (sample 1) and original waste paper cellulose indicated that the crystallinity index of regenerated waste paper cellulose was reduced. Compared with the original waste paper cellulose, the reduction of the hydrogen-bond interaction in the regenerated waste paper cellulose led to a sharpening of the band and a shift of the characteristic absorption peaks from short wavelength to long wavelength in the range of approximately 3000 to $3600 \mathrm{~cm}^{-1}$. Meanwhile, there were no obvious changes at the peaks located at $617 \mathrm{~cm}^{-1}, 1061 \mathrm{~cm}^{-1}, 1373 \mathrm{~cm}^{-1}, 1640 \mathrm{~cm}^{-1}, 2902 \mathrm{~cm}^{-1}$, and $3422 \mathrm{~cm}^{-1}$, which indicated that the chemical structure of cellulose did not change before and after the dissolution.

The dissolution kinetics of fir powder in [AMIM]Cl is illustrated by Fig. 3(b). The transmittance of the peak at $2909 \mathrm{~cm}^{-1}$ indicated that the crystalline degree of 
cellulose in the dissolved fir powder was reduced. Compared with the spectrum of the original fir powder, the band of regenerated fir powder (sample 6) from [AMIM]Cl at $1636 \mathrm{~cm}^{-1}$ was broadened, and the transmittance increased. The same changes appeared at $1266 \mathrm{~cm}^{-1}$ and $1050 \mathrm{~cm}^{-1}$, which are the characteristic absorption peaks of cellulose in the regenerated fir powder. After treatment with alkali, the vast majority of lignin and partial hemicelluloses in the original fir powder are removed. So, the peak at $769 \mathrm{~cm}^{-1}$, which is attributed to the $\mathrm{C}-\mathrm{H}$ bending vibration, disappeared in the regenerated fir powder. The increase in the transmittance of absorption peak at $3397 \mathrm{~cm}^{-1}$ indicated that the content of water in the dissolved fir powder has decreased. The changes that appeared in the spectrum of regenerated fir powder illustrated that the cellulose in the fir powder were partly dissolved. Figure 3(c) presents the spectra of sample 2 and sample 4, which illustrates the effect of dissolved waste paper cellulose on the dissolution of fir powder in [AMIM]Cl. By comparing the two spectra, the changes in absorption peaks at $3383 \mathrm{~cm}^{-1}$, $1645 \mathrm{~cm}^{-1}, 1431 \mathrm{~cm}^{-1}, 1111 \mathrm{~cm}^{-1}$, and $1058 \mathrm{~cm}^{-1}$ indicated that the introduction of dissolved waste paper cellulose had a positive impact on the dissolution of fir powder in [AMIM]Cl.

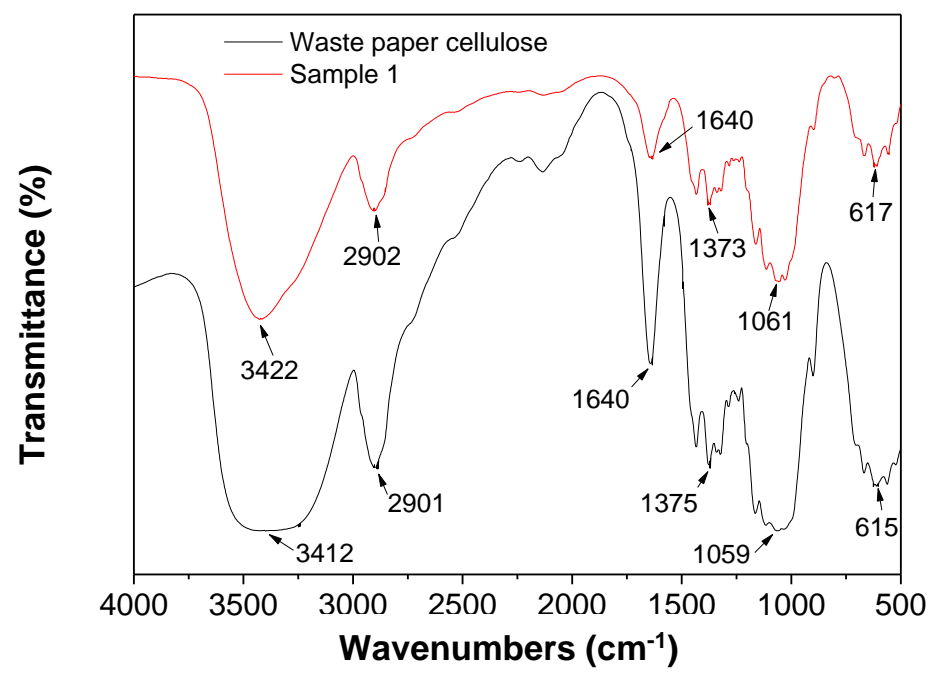

(a)

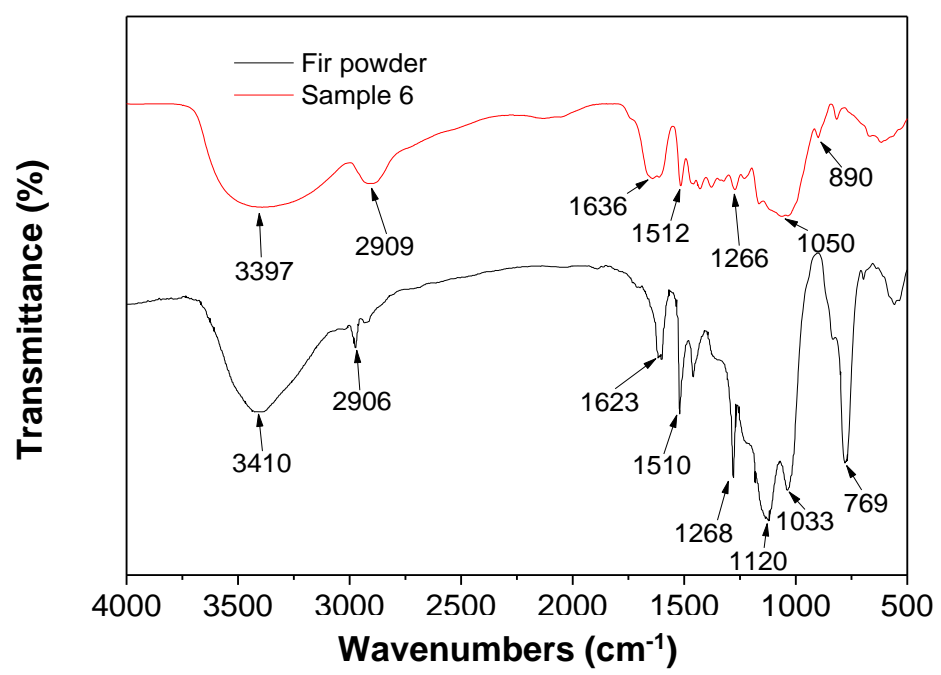

(b) 


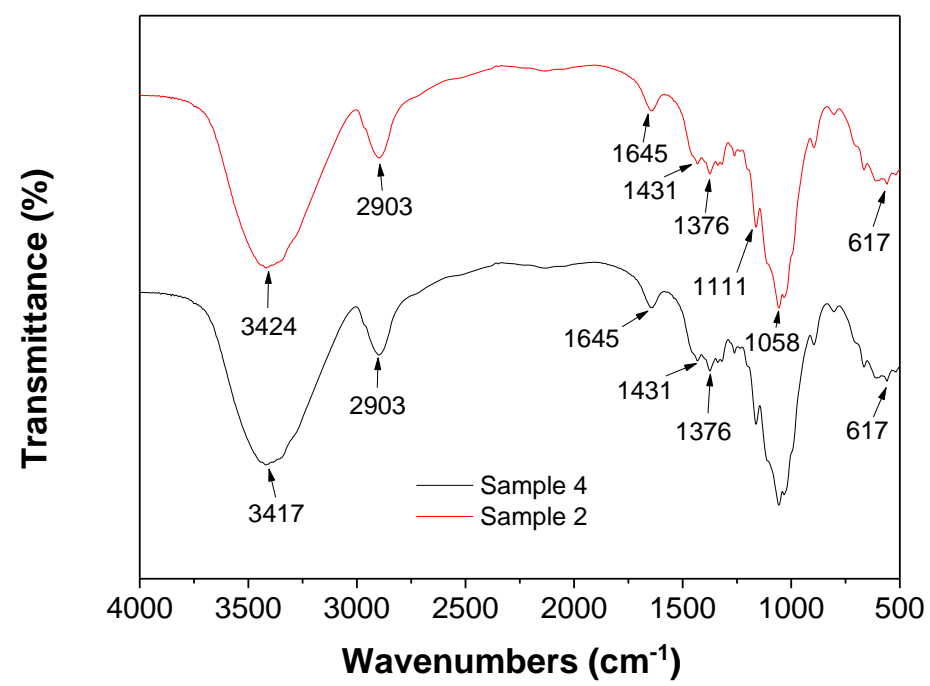

(c)

Fig. 3. FT-IR spectra of (a) original waste paper cellulose and sample 1, (b) original fir powder and sample 6 , and (c) sample 2 and sample 4

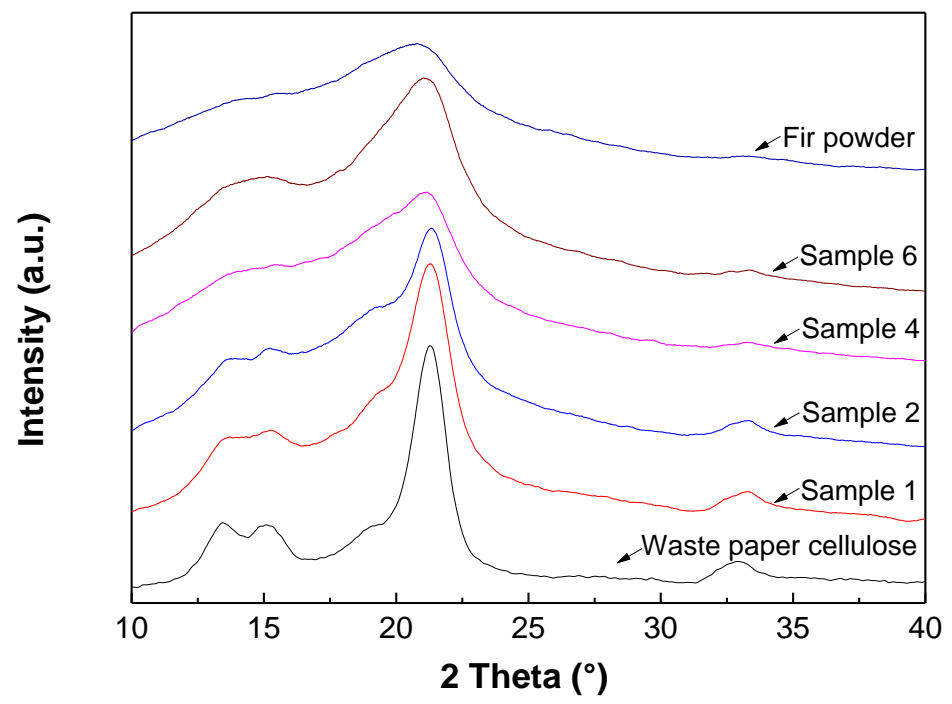

Fig. 4. X-ray spectra of regenerated lignocellulosic materials from [AMIM]CI

Table 2. Crystallinity Indexes of Regenerated Biomass Composite Films

\begin{tabular}{|c|c|}
\hline Trial & Crystallinity Index (\%) \\
\hline 1 & 64.86 \\
\hline 2 & 45.15 \\
\hline 3 & 41.36 \\
\hline 4 & 28.19 \\
\hline 5 & 27.48 \\
\hline 6 & 29.13 \\
\hline
\end{tabular}

\section{XRD Characterization}

The X-ray spectra of regenerated biocomposite films with a different raw material ratio from [AMIM]Cl are illustrated in Fig. 4. After the dissolution of the lignocellulosic material into $[\mathrm{AMIM}] \mathrm{Cl}$, the sample was recovered by pouring the solution into an excess 
of a nonsolvent. The amorphous material was obtained when the regeneration was carried out. Compared with the diffraction peaks of waste paper cellulose, the intensity of the diffraction peaks of regenerated waste paper cellulose (Sample 1) at $33.24^{\circ}, 21.28^{\circ}$, $15.36^{\circ}$, and $13.73^{\circ}$ decreased. The reason is that there was no lignin in the waste paper to obstruct the deconstruction of the ILs on the cellulose crystalline structure. According the XRD curve of fir powder, only a broad, diffuse diffraction peak around $21.16^{\circ}$ was observed. By contrast, the regenerated lignocelluloses from the dissolved fir powder (sample 6) had the crystal form of cellulose II, according to the peaks at $14.84^{\circ}, 20.16^{\circ}$, and $33.24^{\circ}$. These changes demonstrated that cellulose macromolecules were recrystallized as cellulose II after the dissolution of amorphous hemicelluloses and lignin in an ILs solution followed by alkaline extraction. The intensity of the diffraction peaks of regenerated biocomposites, sample 2 and sample 4, exhibited a decrease first and then an increase with the increase of waste paper content in the mixture. As shown in Table 2, the crystallinity indexes $(\mathrm{CrI})$ of waste paper cellulose, wood powder, and regenerated composite films were obtained via Eq. 2.

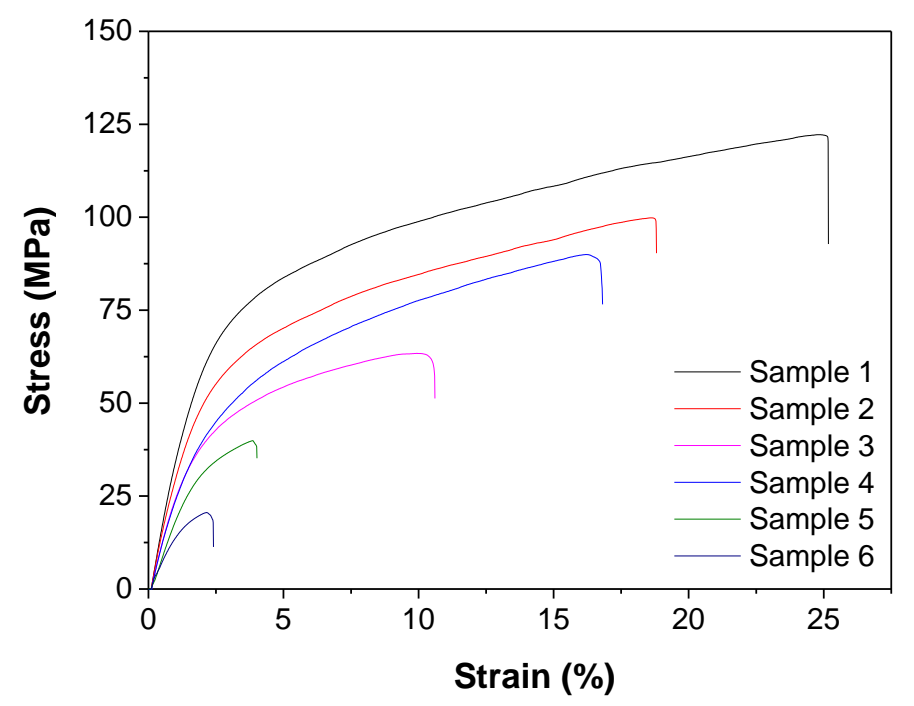

Fig. 5. Mechanical properties of composite films

\section{Mechanical Properties}

The mechanical properties of the composite materials were strongly influenced by the ratio of waste paper cellulose in the biomass composite films. Overall, the tensile strength and the elongation at break of the composite films increased with the increase of waste paper cellulose. As shown in Fig. 5, some important information about the internal structure of the composite materials can be obtained from the stress-strain curves of all the composite films. The composite films underwent the most noticeable changes, showing a large decrease in tensile strength with the increase of wood powder in the lignocelluloses biomass. This indicates the presence of the lignin and hemicelluloses of wood powder had a negative effect on tensile strength and elongation at break of the composite materials. The H-bonding interactions in the regenerated lignocelluloses from the dissolved waste paper cellulose were stronger than those made from dissolved wood powder. The dissolved wood powder, unbound lignin, and hemicelluloses from cellulose resulted in extremely weak composite films. The tensile strength and the elongation at break of the composite films were $90.0 \mathrm{MPa}$ and $16.2 \%$, respectively, when the content 
of the waste paper cellulose was $40 \%$. This reflected that the introduction of the dissolved waste paper cellulose increased the dissolution of the fir powder in [AMIM]Cl and improved the mechanical properties of the composite films.

\section{CONCLUSIONS}

1. Biomass composite films were prepared directly from solutions of raw biomass dissolved in [AMIM]Cl. During dissolution, the components of the lignocellulosic materials remained intact, leading to a whole new range of possibilities to efficiently utilize biomass resources. After dissolution-regeneration treatment, stronger biomass composite films were obtained by using a biomass source with waste paper cellulose and wood powder in the IL.

2. By using a hydrothermal process to treat raw materials, the hemicelluloses and the lignin would be removed to increase the permeability of ILs into the wood powder. The introduction of dissolved waste paper cellulose in ILs increased the dissolution rate of wood powder in [AMIM]Cl. When the dissolved waste paper cellulose content in the mixed lignocellulosic materials was below $40 \%$, the dissolution rate of wood powder increased remarkably with increasing dissolved waste paper cellulose.

3. During the dissolution and regeneration of the waste paper cellulose and wood powder in the ILs, the chemical structure of lignocellulosic materials did not obvious change. Under the influence of ILs, the crystallinity indexes of the regenerated biomass composite films declined.

4. The dissolution of the lignocellulosic materials with a different blending ratio of waste paper and wood powder in ILs was caused by the destruction of inter- and intramolecular hydrogen bonds between lignocelluloses. With the increase of waste paper cellulose, the tensile strength and the elongation at break of the composite films increased overall.

\section{ACKNOWLEDGMENTS}

This work is supported by the Open Fund of Fujian Universities and Colleges Engineering Research Center of Soft Plastic Packaging Technology for Food (G1KF1708), the Provincial Undergraduate Innovation and Entrepreneurship Program of Anhui (Grant No. 201710364081) and National Innovation and Entrepreneurship Training Program for College Students (Grant No. 201810364069).

\section{REFERENCES CITED}

Abdulkhani, A., Marvast, E. H., Ashori, A., and Karimi, A. N. (2013). "Effects of dissolution of some lignocellulosic materials with ionic liquids as green solvents on mechanical and physical properties of composite films," Carbohyd. Polym. 95(1), 5763. DOI: 10.1016/j.carbpol.2013.02.040 
Al Mualla, S., Farahat, R., Basmaji, P., de Olyveira, G. M., Costa, L. M. M., da Costa Oliveira, J. D., and Francozo, G. B. (2016). "Study of nanoskin ECM-bacterial cellulose wound healing/United Arab Emirates," Journal of Biomaterials and Nanobiotechnology 7(2), 109-117. DOI: 10.4236/jbnb.2016.72012

Behera, S., Arora, R., Nandhagopal, N., and Kumar, S. (2014). "Importance of chemical pretreatment for bioconversion of lignocellulosic biomass," Renew. Sust. Energ. Rev. 36, 91-106. DIO: 10.1016/j.rser.2014.04.047

Bhutto, A. W., Qureshi, K., Harijan, K., Abro, R., Abbas, T., Bazmi, A. A., and Yu, G. (2017). "Insight into progress in pre-treatment of lignocellulosic biomass," Energy 122, 724-745. DOI: 10.1016/j.energy.2017.01.005

Binder, J. B., and Raines, R. T. (2010). "Fermentable sugars by chemical hydrolysis of biomass," P. Natl. Acad. Sci. USA 107(10), 4516-4521. DOI: 10.1073/pnas.0912073107

Brodeur, G., Yau, E., Badal, K., Collier, J., Ramachandran, K. B., and Ramakrishnan, S. (2011). "Chemical and physicochemical pretreatment of lignocellulosic biomass: A review," Enzyme Research 2011, 1-17. DOI: 10.4061/2011/787532

da Silva, A. S. A., Inoue, H., Endo, T., Yano, S., and Bon, E. P. (2010). “Milling pretreatment of sugarcane bagasse and straw for enzymatic hydrolysis and ethanol fermentation," Bioresource Technol. 101(19), 7402-7409. DOI: 10.1016/j.biortech.2010.05.008

Fort, D. A., Remsing, R. C., Swatloski, R. P., Moyna, P., Moyna, G., and Rogers, R. D. (2007). "Can ionic liquids dissolve wood? Processing and analysis of lignocellulosic materials with 1-n-butyl-3-methylimidazolium chloride," Green Chem. 9(1), 63-69. DOI: 10.1039/B607614A

Himmel, M. E., Ding, S. Y., Johnson, D. K., Adney, W. S., Nimlos, M. R., Brady, J. W., and Foust, T. D. (2007). "Biomass recalcitrance: Engineering plants and enzymes for biofuels production,” Science 315(5813), 804-807. DOI: 10.1126/science.1137016

Imman, S., Arnthong, J., Burapatana, V., Laosiripojana, N., and Champreda, V. (2013). "Autohydrolysis of tropical agricultural residues by compressed liquid hot water pretreatment," Appl. Biochem. Biotech. 170(8), 1982-1995. DOI: 10.1007/s12010013-0320-1

Jönsson, L. J., and Martín, C. (2016). "Pretreatment of lignocellulose: Formation of inhibitory by-products and strategies for minimizing their effects," Bioresource Technol. 199, 103-112. DOI: 10.1016/j.biortech.2015.10.009

Kumar, R., Sharma, R. K., and Singh, A. P. (2017). "Cellulose based grafted biosorbents - Journey from lignocellulose biomass to toxic metal ions sorption applications - A review," J. Mol. Liq. 232, 62-93. DOI: 10.1016/j.molliq.2017.02.050

Li, B., Asikkala, J., Filpponen, I., and Argyropoulos, D. S. (2010). "Factors affecting wood dissolution and regeneration of ionic liquids," Ind. Eng. Chem. Res. 49(5), 24772484. DOI: $10.1021 / \mathrm{ie} 901560 \mathrm{p}$

Li, C., Wang, Q., and Zhao, Z. K. (2008). "Acid in ionic liquid: An efficient system for hydrolysis of lignocelluloses," Green Chem. 10(2), 177-182. DOI: 10.1039/B711512A

Liu, C., and Wyman, C. E. (2005). "Partial flow of compressed-hot water through corn stover to enhance hemicellulose sugar recovery and enzymatic digestibility of cellulose," Bioresource Technol. 96(18), 1978-1985. DOI: 10.1016/j.biortech.2005.01.012

Mahmood, H., Moniruzzaman, M., Yusup, S., and Welton, T. (2017). "Ionic liquids assisted processing of renewable resources for the fabrication of biodegradable 
composite materials," Green Chem. 19(9), 2051-2075. DOI: 10.1039/C7GC00318H

Mood, S. H., Golfeshan, A. H., Tabatabaei, M., Jouzani, G. S., Najafi, G. H., Gholami, M., and Ardjmand, M. (2013). "Lignocellulosic biomass to bioethanol, a comprehensive review with a focus on pretreatment," Renew. Sust. Energ. Rev. 27, 7793. DOI: $10.1016 /$ j.rser.2013.06.033

Nemestóthy, N., Megyeri, G., Bakonyi, P., Lakatos, P., Koók, L., Polakovic, M., Gubicza L. and Bélafi-Bakó, K. (2017). "Enzyme kinetics approach to assess biocatalyst inhibition and deactivation caused by [bmim] $[\mathrm{Cl}]$ ionic liquid during cellulose hydrolysis," Bioresource Technol. 229, 190-195. DOI: 10.1016/j.biortech.2017.01.004

Qin, Y., Lu, X., Sun, N., and Rogers, R. D. (2010). "Dissolution or extraction of crustacean shells using ionic liquids to obtain high molecular weight purified chitin and direct production of chitin films and fibers," Green Chem. 12(6), 968-971. DOI: 10.1039/C003583A

Rajeev, A., Deshpande, A. P., and Basavaraj, M. G. (2018). "Rheology and microstructure of concentrated microcrystalline cellulose (MCC)/1-allyl-3methylimidazolium chloride (AmimCl)/water mixtures," Soft Matter 14(37), 76157624. DOI: $10.1039 / \mathrm{C} 8 \mathrm{SM} 01448 \mathrm{E}$

Remsing, R. C., Swatloski, R. P., Rogers, R. D., and Moyna, G. (2006). "Mechanism of cellulose dissolution in the ionic liquid 1-n-butyl-3-methylimidazolium chloride: $\mathrm{A}^{13} \mathrm{C}$ and ${ }^{35 / 37} \mathrm{Cl}$ NMR relaxation study on model systems," Chem. Commun. (12), 12711273. DOI: 10.1039/B600586C

Swatloski, R. P., Spear, S. K., Holbrey, J. D., and Rogers, R. D. (2002). "Dissolution of cellose with ionic liquids," J. Am. Chem. Soc. 124(18), 4974-4975. DOI: 10.1021/ja025790m

Wang, X., Li, H., Cao, Y., and Tang, Q. (2011). "Cellulose extraction from wood chip in an ionic liquid 1-allyl-3-methylimidazolium chloride (AmimCl)," Bioresource Technol. 102(17), 7959-7965. DOI: 10.1016/j.biortech.2011.05.064

Xie, H., King, A., Kilpelainen, I., Granstrom, M., and Argyropoulos, D. S. (2007). "Thorough chemical modification of wood-based lignocellulosic materials in ionic liquids," Biomacromolecules 8(12), 3740-3748. DOI: 10.1021/bm700679s

Yoo, C. G., Pu, Y., and Ragauskas, A. J. (2017). "Ionic liquids: Promising green solvents for lignocellulosic biomass utilization," Current Opinion in Green and Sustainable Chemistry 5, 5-11. DOI: 10.1016/j.cogsc.2017.03.003

Article submitted: October 7, 2018; Peer review completed: December 30, 2018; Revised version received and accepted: February 3, 2019; Published: February 8, 2019.

DOI: $10.15376 /$ biores. 14.2.2584-2595 